\title{
Studies on character association among quality traits and yield components in Basmati Rice (Oryza sativa L.)
}

\author{
Amod Kumar \\ Department of Agricultural Botany, R.M.P. (P.G.) College, Gurukul Narsan, Haridwar-247670 \\ (Uttarakhand), India \\ Shiv Kumar* \\ Department of Agricultural Botany, R.M.P. (P.G.) College, Gurukul Narsan, Haridwar-247670 \\ (Uttarakhand), India \\ Sarvendra Singh \\ Department of Agricultural Entomology, R.M.P. (P.G.) College, Gurukul Narsan, Haridwar- \\ 247670 (Uttarakhand), India

\section{Janeshwar Prasad} \\ Department of Agricultural Botany, R.M.P. (P.G.) College, Gurukul Narsan, Haridwar-247670 \\ (Uttarakhand), India \\ A S Jeena \\ Department of Genetics and Plant Breeding, G B Pant University of Agriculture and Technology, \\ Pantnagar-263145 (Uttarakhand), India \\ M C Upreti \\ Department of Genetics and Plant Breeding, G B Pant University of Agriculture and Technology, \\ Pantnagar-263145 (Uttarakhand), India \\ *Corresponding author. E mail: shivkumar.gkl@gmail.com
}

\section{How to Cite}

Kumar, A. et al. (2020). Studies on character association among quality traits and yield components in Basmati Rice (Oryza sativa L.). Journal of Applied and Natural Science, 12 (3): 292 - 298. https://doi.org/10.31018/jans.v12i3.2294

\begin{abstract}
Rice is most important food crop of India and grown in different regions with differential consumer preferences for grain size, shape, aroma and cooking qualities. Therefore, crop improvement in rice not only focused on yield but also to enhance quality. Hence the present investigation was carried out with an objective of assessing the character association among twenty-two morphological and quality characters of thirty basmati rice (Oryza sativa L) genotypes. Correlation analysis revealed that Seed yield was significantly and positively associated with days to maturity $\left(0.330^{* *}\right)$, number of tillers per plant $\left(0.434^{* *}\right)$, number of grains per panicle $\left(0.358^{\star *}\right)$, grain weight per panicle $\left(0.410^{* *}\right)$, and flag leaf length $\left(0.258^{*}\right)$. The days to maturity exhibited a significant positive correlation with plant height, panicle length, grain weight per plant, kernel length before cooking, kernel length after cooking and L: B ratio. Tiller per plant reflected the positive and significant association with a number of grains per panicle, grain weight per panicle and grain weight per plant. Flag leaf length showed a significant positive correlation with a number of grains per panicle and grain weight per plant, while Grains per panicle was positively and significantly associated with grain weight per panicle, grain weight per plant and kernel breadth before cooking. Grain weight per panicle exhibited a significant positive association with grain yield per plant $\left(0.410^{* *}\right)$, kernel breadth before cooking $\left(0.381^{* *}\right)$, 100 grain weight $\left(0.240^{*}\right)$ and 100 kernel weight $\left(0.210^{\star}\right)$. These characters could be utilized to form a selection index for improvement of the basmati rice.
\end{abstract}

Keywords: Correlation, Oryza sativa L., Paddy, quality, Yield

\section{INTRODUCTION}

India is endowed with an astonishing genetic diversity of rice. Basmati rice is one of the distinguished groups that have high demand and acceptance whole over the world. Basmati rice is traditionally grown in the Himalayan foothill regions of India and Pakistan (Bligh,
2000). Basmati rice export is a good source of foreign exchange in 2018-19, India exported to $65 \%$ of the overseas basmati rice market (APEDA, 2020). There is a pressure to increase yield of basmati rice to fulfil the local demand and increase the foreign exchange keeping the quality of basmati intact. Yield is a com- 
plex trait it depends on multiple factors. Thus, the knowledge of interrelationships between yield and its contributing factors improves the efficiency of breeding programs through the use of effective selection indices.

Association studies reveal the mutual relationship among different plant attributes and determine the component characters on which selection can be based for yield improvement. While selecting the suitable plant type, correlation studies would provide reliable information in natural extent and the direction of the selection, especially when the breeder needs to combine high yield potentials with desirable agronomic traits and grain quality characters. A positive value of correlation shows at the changes of two variables are in the same direction, i.e. the high value of one variable are associated with high values of other and viceversa (Hossain et al. 2015). When correlation is negative, the improvements are in opposite directions, i.e. high values of one variable are associated with low values of others. The breeder is always looking for a selection of superior genotypes based on phenotypic expression. However, the quantitative characters, are influenced by the environment, thereby the phenotypic expression may be misleading; hence interrelationship at the genotypic level is more reliable. Information regarding the nature and extent of association of morphological characters would be helpful in developing suitable plant type, in addition to the improvement of yield a complex character for which direct selection is not effective (Chaudhary et al., 2020).

The better way of exploiting genetic correlation and path coefficient with several traits having high heritability is to construct a selection index that combines information on all characters associated with the dependent variable (Kumar et al., 2011). Efforts are to be taken with a systematic research approach to exploit the yield potential by direct and indirect selection. The use of correlation coefficient and path analysis is to establish the extent of association between yield and yield components and other characters and for fixing up the characters which are having a decisive role in influencing the yield. The wide difference between genotypic and phenotypic correlations between two characters is due to the dual nature of phenotypic correlation, which is determined by genotypic and environmental correlations and heritability of the characters. Hence, the present investigation was carried out to elucidate the interrelationship among the yield components and quality characters in basmati rice.

\section{MATERIALS AND METHODS}

Study area: The present study was conducted at Research farm of R.M.P. P.G. College, Gurukul Narsan, Haridwar (Uttarakhand) with 30 improved genotypes of basmati rice during Kharif 2019. The Gurukul Narsan is situated in the foothills of Shivalik range of Himalaya at $29.7^{\circ} \mathrm{N}$ latitude, $77.85^{\circ} \mathrm{E}$ longitude and at an elevation of $261 \mathrm{~m}$ amsl, which falls in the humid subtropical climate zone. The experiment was conducted to elucidate the interrelationship among yield components and quality parameters in basmati rice. The experimental material comprised of 30 genotypes of basmati rice (Oryza sativa L.) was planted in a randomized complete block design with three replications in the plot size of $2 \mathrm{~m}^{2}$ keeping $20 \times 15 \mathrm{~cm}$ spacing. The observations were recorded on a random sample of 10 plants from each plot for 22 quantitative characters viz., Days to $50 \%$ flowering, days to maturity, plant height $(\mathrm{cm})$, number of tillers per plant, panicle length (cm), flag leaf length $(\mathrm{cm})$, flag leaf with $(\mathrm{cm})$, number of grains per panicle, grain weight per panicle (g), 100 grain weight (g), 100 kernel weight (g), hulling (\%), kernel length before cooking $(\mathrm{mm})$, kernel breadth before cooking $(\mathrm{mm})$, kernel length after cooking $(\mathrm{mm})$, kernel breadth after cooking $(\mathrm{mm}), \mathrm{L}: \mathrm{B}$ ratio, kernel elongation ratio, breath increase ratio after cooking, 100 kernel weight after cooking (g), water absorb by 10 gm kernel (ml), grain weight per plant (g). Observations on cooking quality characters were recorded as suggested by Mohapatra and Bal (2005).

Statistical analysis: Analysis of variance was carried out following Panse and Sukhatme (1967) and correlation coefficients between all possible pairs of characters were estimated at the genotypic and phenotypic level. The analysis of variance and covariance was used for the estimation of the correlation coefficient as suggested by Searle (1961). The estimated values were compared with the table values of the correlation coefficient to test the significance of the correlation coefficient prescribed by Fisher and Yates (1967).

\section{RESULTS AND DISCUSSION}

The estimates of correlation coefficients (Table 1) revealed that, in general, the genotypic and the phenotypic correlation coefficient among yield components and quality characters in basmati rice showed a similar trend, but genotypic correlation coefficients were of higher in magnitude than the corresponding phenotypic correlation. Genotypic correlation coefficients between grain yield per plant and other quantitative attributing to yield showed that seed yield was significantly and positively associated with days to maturity $\left(0.330^{* *}\right)$, number of tillers per plant $\left(0.434^{* *}\right)$, number of grains per panicle $\left(0.358^{* *}\right)$, grain weight per panicle $\left(0.410^{* *}\right)$, and flag leaf length $\left(0.258^{*}\right)$. Sravan et al. (2016) also reported a highly significant positive correlation of Grain yield with days to $50 \%$ flowering, days to maturity, plant height, tillers per plant, panicle length, grains per panicle and kernel breadth after 


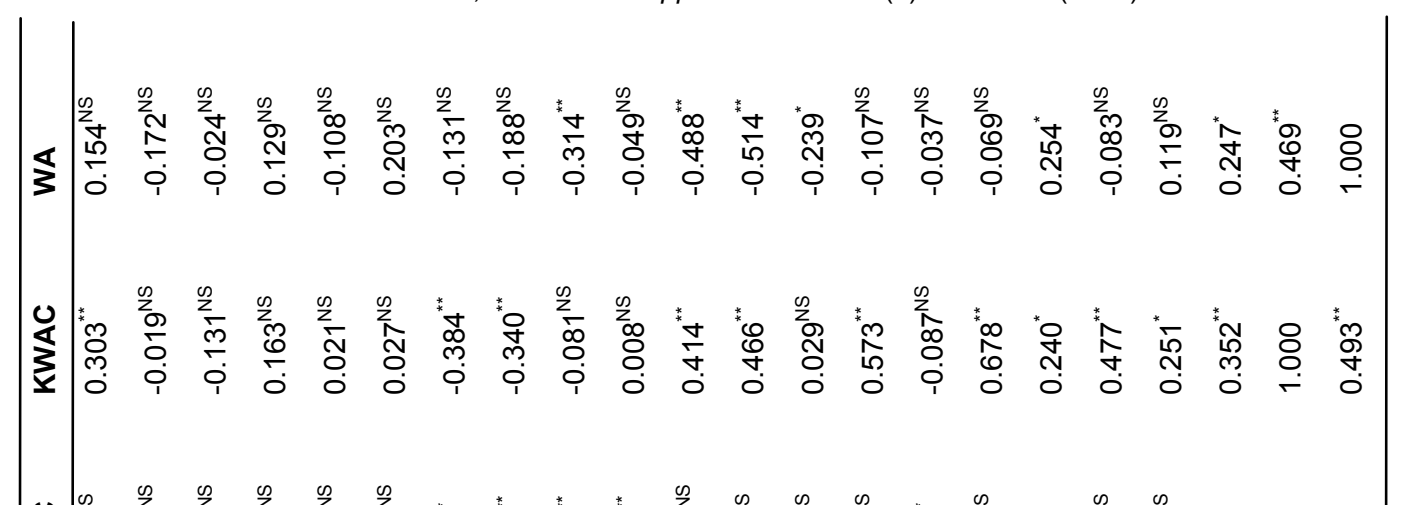

نे

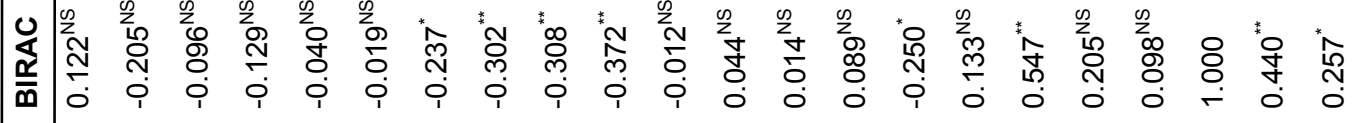

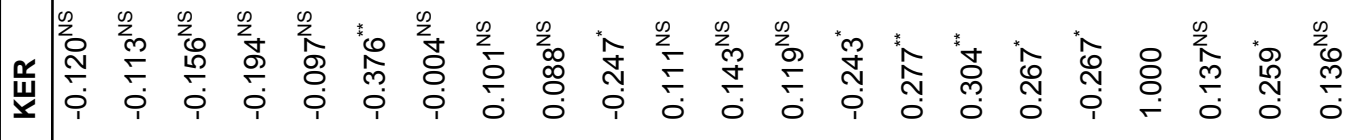

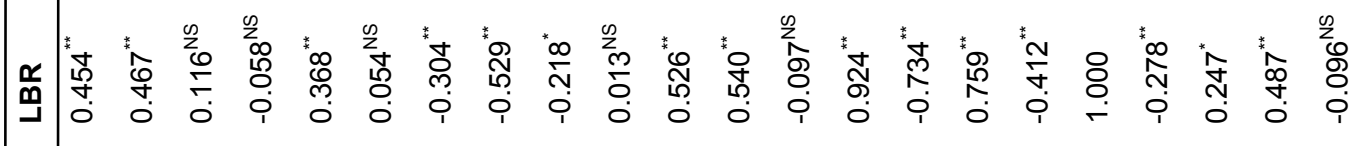

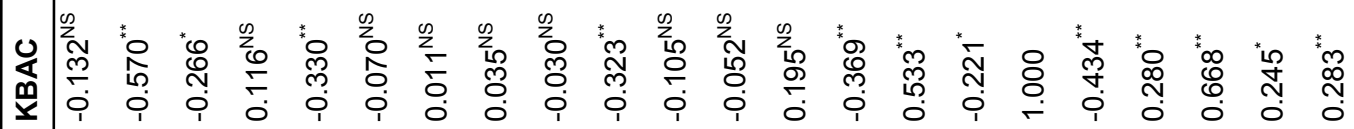

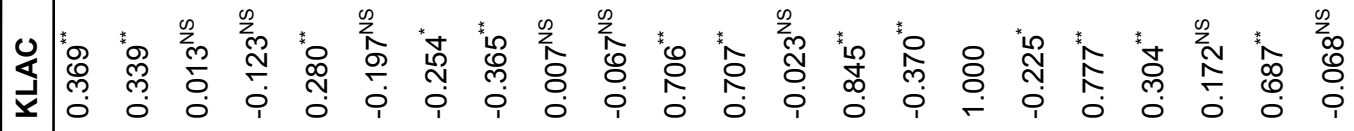

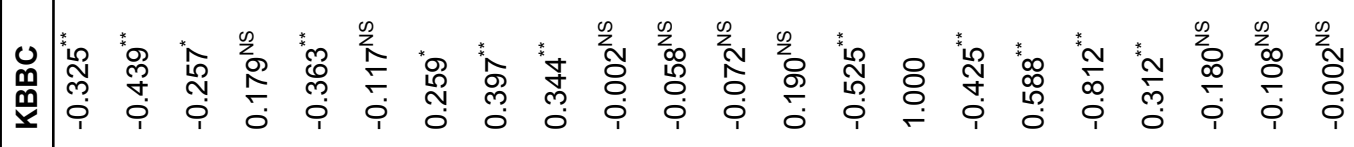

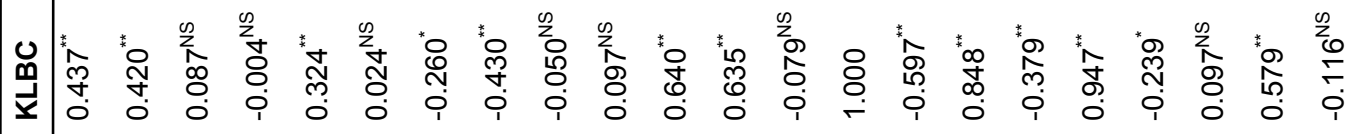

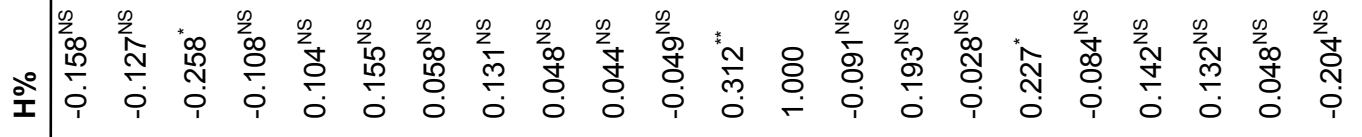

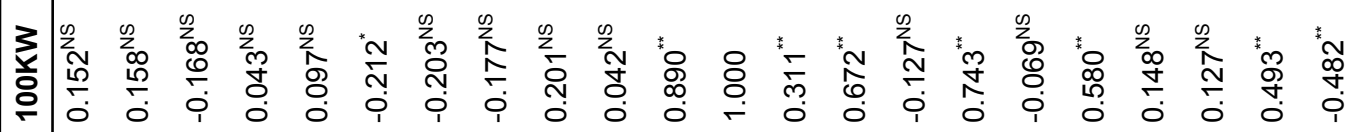

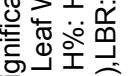

क⿺辶一兀

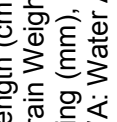

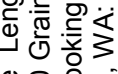

잉ㅇㅇㅇ

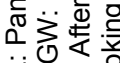

승응ㅎㅇㅇ

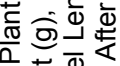

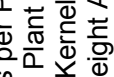

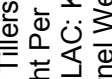

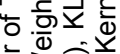

ब

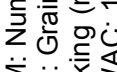

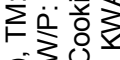

हो 0 잉

흥웡

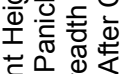

西 $\frac{1}{2}$

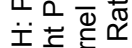

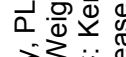

.

$\sum_{0}$ نं

옹

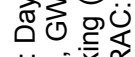

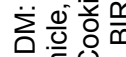

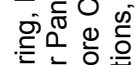

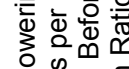

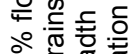

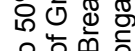

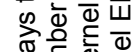

نั

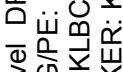

a

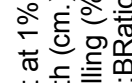

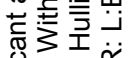

岁喜咅

$\bar{\Phi} \div 30$

屯

: 
cooking in rice. Devi et al. (2017) recorded significant positive association between seed yield and grains per panicle, plant height, flag leaf length, number of tillers per plant, flag leaf width and panicle length in rice.

In the present study, grain yield also showed a significant and negative correlation with kernel breadth after cooking $\left(-0.335^{* *}\right)$, breadth increase ratio after cooking $\left(-0.461^{* *}\right)$ and kernel elongation ratio $\left(-0.249^{*}\right)$. It can be inferred from the results that selection for higher values of days to maturity, number of tillers per plant, number of grains per panicle, grain weight per panicle and flag leaf length will enhance the grain yield in basmati rice. Selection based on these traits will reduce the kernel breadth after cooking and breadth increase ratio after cooking, which is also desirable for basmati quality but reduction in kernel elongation ratio due to indirect selection based on an above morphological trait is not in favour of basmati quality. Hence careful selection is required in this case. Days to flowering exhibited highly significant and positive correlation with days to maturity $\left(0.682^{* *}\right)$, plant height $\left(0.417^{* *}\right)$, panicle length $\left(0.398^{* *}\right)$, kernel length before cooking $\left(0.447^{* *}\right)$, kernel length after cooking $\left(0.378^{* *}\right), \mathrm{L}: \mathrm{B}$ ratio $\left(0.481^{* *}\right)$ and 100 kernel weight after cooking $\left(0.313^{* *}\right)$ while it showed significant and positive correlation with 100 grain weight $\left(0.265^{\star}\right)$. Whereas days to flowering showed a highly significant and negative correlation with a number of grains per panicle $\left(-0.499^{* *}\right)$, grain weight per panicle $\left(-0.271^{* *}\right)$ and kernel breadth before cooking ($\left.0.359^{* *}\right)$. The days to maturity exhibited highly significant and positive correlation with plant height $\left(0.432^{* *}\right)$, panicle length $\left(0.483^{* *}\right)$, grain weight per plant $\left(0.330^{* *}\right)$, kernel length before cooking $\left(0.434^{* *}\right)$, kernel length after cooking $\left(0.347^{* *}\right)$ and $\mathrm{L}: \mathrm{B}$ ratio $\left(0.493^{* *}\right)$. However, it showed a significant and negative correlation with kernel breadth before cooking $\left(-0.517^{* *}\right)$, kernel breadth after cooking ($\left.0.595^{* *}\right)$ and breadth increase ratio after cooking ($\left.0.255^{\star}\right)$. Plant height showed a highly significant and positive correlation with panicle length $\left(0.547^{* *}\right)$, while it showed a highly significant negative correlation with hulling \% $\left(-0.279^{* *}\right)$, kernel breadth before cooking ($\left.0.291^{* *}\right)$ and kernel breadth after cooking $\left(-0.271^{* *}\right)$. Tiller per plant showed a highly significant positive correlation with a number of grains per panicle $\left(0.300^{* *}\right)$, grain weight per panicle $\left(0.385^{\star *}\right)$ and grain weight per plant $\left(0.434^{* *}\right)$. It showed a significant positive correlation with kernel breadth before cooking $\left(0.212^{*}\right)$, whereas it showed a significantly negative correlation with panicle length $\left(-0.224^{*}\right)$ and flag leaf breadth $\left(-0.257^{*}\right)$. Panicle length exhibited a highly significant and positive correlation with flag leaf length $\left(0.305^{* *}\right.$, kernel length before cooking $\left(0.325^{* *}\right)$, kernel length after cooking $\left(0.281^{* *}\right)$ and $L: B$ ratio $\left(0.378^{* *}\right)$ while it showed a highly significant and negative correlation with kernel breadth before cooking ($\left.0.414^{* *}\right)$ and kernel breadth after cooking $\left(-0.338^{* *}\right)$. Flag leaf length showed a significant and positive correlation with a number of grains per panicle $\left(0.217^{*}\right)$ and grain weight per plant $\left(0.258^{\star}\right)$. It showed a highly significant and negative correlation with 100 grain weight $\left(-0.343^{* *}\right)$ and kernel elongation ratio ($\left.0.393^{* *}\right)$, however, it showed a significant and negative correlation with 100 kernel weight $\left(-0.219^{*}\right)$. Flag leaf breadth showed a highly significant positive correlation with kernel breadth before cooking $\left(0.311^{* *}\right)$ and significant and positive correlation with a number of grains per panicle $\left(0.242^{*}\right)$. It showed a highly significant and negative correlation with 100 kernel weight ($\left.0.277^{* *}\right)$, kernel length before cooking $\left(-0.309^{* *}\right)$, kernel length after cooking $\left(-0.307^{* *}\right), \mathrm{L}$ : B ratio $\left(-0.356^{* *}\right)$ and breadth increase ratio after cooking $\left(-0.322^{* *}\right)$. In comparison, it showed a significant and negative correlation with 100 grain weight $\left(-0.212^{*}\right)$. Grains per panicle showed a highly significant and positive correlation with grain weight per panicle $\left(0.817^{* *}\right)$, grain weight per plant $\left(0.358^{* *}\right)$ and kernel breadth before cooking $\left(0.453^{* *}\right)$, while it showed a highly significant and negative correlation with kernel length before cooking $\left(-0.431^{* *}\right)$, kernel length after cooking ($\left.0.366^{* *}\right)$, L: B ratio $\left(-0.545^{* *}\right)$ and breadth increase ratio after cooking $\left(-0.371^{* *}\right)$. It showed a significant and negative correlation with 100 grain weight ($\left.0.211^{*}\right)$. Grain weight per panicle showed a significant positive correlation with grain yield per plant $\left(0.410^{* *}\right)$, kernel breadth before cooking $\left(0.381^{* *}\right), 100$ grain weight $\left(0.240^{*}\right)$ and 100 kernel weight $\left(0.210^{*}\right)$ while it showed significant and negative correlation with breadth increase ratio after cooking $\left(-0.359^{* *}\right)$, water absorb by $10 \mathrm{~g}$ kernel $\left(-0.333^{* *}\right)$ and L:B ratio ($\left.0.221^{*}\right) .100$ grain weight showed a highly significant and positive correlation with 100 kernel weight $\left(0.923^{* *}\right)$, kernel length before cooking $\left(0.725^{* *}\right)$, L: B ratio $\left(0.549^{* *}\right)$ and 100 kernel weight after cooking $\left(0.424^{* *}\right)$, while it showed a highly significant and negative correlation with water absorb by $10 \mathrm{~g}$ kernel ($\left.0.500^{* *}\right)$.

100 kernel weight showed a highly significant and positive correlation with hulling $\%\left(0.311^{* *}\right)$, kernel length before cooking $\left(0.672^{* *}\right)$, kernel length after cooking $\left(0.743^{* *}\right)$, L: B ratio $\left(0.580^{* *}\right)$ and 100 kernel weight after cooking $\left(0.493^{* *}\right)$. However, it showed a highly significant and negative correlation with water absorb by $10 \mathrm{~g}$ kernel $\left(-0.482^{* *}\right)$. Hulling per cent exhibited a significant and positive correlation with kernel breadth after cooking $\left(0.227^{*}\right)$. Kernel length before cooking exhibited a highly significant and positive correlation with kernel length after cooking $\left(0.848^{* *}\right)$, L: B ratio $\left(0.947^{* *}\right)$ and 100 kernel weight after cooking 
$\left(0.579^{* *}\right)$, while it showed a highly significant and negative correlation with kernel breadth before cooking ($\left.0.597^{* *}\right)$, kernel breadth after cooking $\left(-0.379^{* *}\right)$ and significant and negative correlation with kernel elongation ratio $\left(-0.239^{*}\right)$. Kernel breadth before cooking showed a highly significant and positive correlation with kernel breadth after cooking $\left(0.588^{* *}\right)$ and kernel elongation ratio $\left(0.312^{* *}\right)$. However, it showed a high signification and negative correlation with kernel length after cooking $\left(-0.425^{\star \star}\right)$ and L: B ratio $\left(-0.812^{\star \star}\right)$. Kernel length after cooking showed a highly significant and positive correlation with L: B ratio $\left(0.777^{\star *}\right)$, kernel elongation ratio $\left(0.304^{* *}\right)$ and 100 kernel weight after cooking $\left(0.687^{* *}\right)$ however it showed a negative correlation with kernel breadth after cooking $\left(-0.225^{*}\right)$. Devi et al. (2017) also found a significant positive association between kernel length after cooking and L: B ratio, elongation ratio, hulling per cent and milling per cent in rice. Kernel breadth after cooking showed a highly significant and positive correlation with breadth increase ratio after cooking $\left(0.668^{\star *}\right)$, kernel elongation ratio $\left(0.280^{* *}\right)$ and water absorb by $10 \mathrm{~g}$ kernel $\left(0.283^{* *}\right)$ and significant association with 100 kernel weight after cooking $\left(0.245^{*}\right)$, while it showed a highly significant and negative correlation with $\mathrm{L}$ : $\mathrm{B}$ ratio ($\left.0.434^{* *}\right)$. L: B ratio exhibited a highly significant and positive correlation with 100 kernel weight after cooking $\left(0.487^{* *}\right)$ and significant positive correlation with breadth increase ratio after cooking $\left(0.247^{*}\right)$. However, it showed a highly significant and negative correlation with kernel elongation ratio $\left(-0.278^{* *}\right)$. Kernel elongation ratio showed a significant and positive correlation with 100 kernel weight after cooking $\left(0.259^{*}\right)$. Breadth increase ratio after cooking exhibited a highly significant and positive correlation with kernel weight after cooking $\left(0.440^{* *}\right)$ and significant correlation with water absorb by $10 \mathrm{~g}$ kernel $\left(0.257^{\star}\right)$. Kernel weight after cooking showed highly significant association with water absorb by $10 \mathrm{~g}$ kernel $\left(0.493^{* *}\right)$.

Genotypic correlation coefficients were of higher in magnitude than the corresponding phenotypic correlation coefficients, which might be due to masking or modifying effect of environment (Chaudhary et al. 2020). Very close values of genotypic and phenotypic correlations were also observed by Bhattachariya et al. (2007) in rice for seed yield with a number of panicle per plant, grains per panicle and 100 seed weight. Seed yield was significantly and positively associated with days to maturity, number of tillers per plant, number of grains per panicle, grain weight per panicle $(g)$, and flag leaf length (cm). Akinwale et al. (2011) reported a positive correlation of grain yield with tillers per plant, panicle weight and grains per panicle in rice. Similarly, Kumar et al. (2011) found a highly significant positive association of grain yield with tillers per plant, harvest index, biological yield L: B ratio and significant positive correlation with 1000 grain weight in rice. In the present study it was found that these characters further associated significantly and positively with morphological characters such as plant height $(\mathrm{cm})$, panicle length $(\mathrm{cm})$, number of grains per panicle, grain weight per panicle $(\mathrm{g})$, grain weight per plant $(\mathrm{g})$, 100 grain weight and quality parameters viz., 100 kernel weight, kernel length before cooking $(\mathrm{mm})$, kernel breadth before cooking $(\mathrm{mm})$, kernel length after cooking $(\mathrm{mm})$ and $\mathrm{L}$ : B ratio, Thus, selection for a higher yield on the basis of above characters would be reliable. Similar findings were also reported in rice by Krishnamurthy and Kumar (2012), Kumar and Verma (2015), and Tripathi et al. (2018) indicating a positive correlation between yield components such as grains per panicle, panicle weight or length, a number of productive tillers etc. along with positive association with quality parameters viz., kernel length before and after cooking, L: B ratio, water absorption etc. The different authors reported different combinations of morphological and quality characters in their study, which are different from the present investigation, but all reports support a similar trend to an association between morphological and quality parameters.

\section{Conclusion}

In the present study with basmati rice (Oryza sativa L.), the significant positive correlation of grain yield with days to maturity, number of tillers per plant, number of grains per panicle, grain weight per panicle (g), and flag leaf length $(\mathrm{cm})$ and significant positive association of these yield components among themselves and with morphological and quality parameters indicated that selection indices based on days to maturity, number of tillers per plant, plant height $(\mathrm{cm})$, flag leaf length $(\mathrm{cm})$ panicle length $(\mathrm{cm})$, number of grains per panicle, grain weight per panicle $(\mathrm{g})$, grain weight per plant (g), 100 grain weight, 100 kernel weight, kernel length before cooking $(\mathrm{mm})$, kernel breadth before cooking $(\mathrm{mm})$, kernel length after cooking $(\mathrm{mm})$ and $L: B$ ratio, could be utilized for improvement of basmati rice genotypes for yield as well as quality. These characters will be helpful in varietal development in basmati rice because selection in favour of morphological indices will automatically enhance the quality parameters.

\section{REFERENCES}

1. Akinwale, M.C., Gregoria, G., Nwilene, F., Akinyele, B.O., Ogunbayo S.A. and Odiyi A.C. (2011). Heritability and correlation coefficient analysis for yield and its components in rice (Oryza sativa L.) African Journal of Plant Science. 5(3):207-212.

2. APEDA (2020). India Exports Statistics APEDA products. Retrieved on 10 June 2020,http://agriexchange.ap 
eda.gov.in/indexp/genReport_combined.aspx\#content

3. Bhattachariya R, Roy B., Kabi M.C., Basu A.K. ( 2007). Character association and path analysis and path analysis of seed yield and Its attributes in rice as affected by bioinoculums under tropical environment. Trop Agric Res Extn 10, 23-28.

4. Bligh, H.F.J. (2000). Detection of adulteration of Basmati rice with non-premium long-grain rice. International Journal of Food Science and Technology, 35, 257-265.

5. Chaudhary, V., Kumar, S., Singh, S., Prasad, J., Jeena, A.S. and Upreti, M.C.( 2020). Variability, character association and path analysis in wheat (Triticum aestivum L.). $J$. Pharmacognosy and Phytochemistry. 9(3): 1859-1863

6. Devi, K. R., Chandra, B. S., Lingaiah N., Hari Y. and Venkanna V. (2017). Analysis of variability, correlation and path coefficient studies for yield and quality traits in rice (Oryza Sativa L.) Agricultural Science Digest. 37(1):1-9.

7. Fisher R A and Yates F. (1967). Statistical tables for Biological, Agricultural and Medical Research, Longmen Group Limited, London.

8. Hossain, S., Haque, M. and Rahman, J. (2015). Genetic variability, correlation and path coefficient analysis of morphological traits in some extinct local Aman rice (Oryza sativa L). Rice Research: Open Access

9. Krishnamurthy H.T., and Kumar H.D.M. (2012). Correlation and path coefficient studies of some physiological traits among indigenous aromatic rice (Oryza sativa L) cultivars. Agricultural \& Biological Research. 28(2):120- 127.

10.Kumar, A. and Verma, O.P. (2015). Correlation and path coefficient analysis in certain quantitative traits in rice (Oryza sativa L.) under saline-alkaline condition. Res. Envi. Life Sci. 8(3):443-446

11.Kumar, Y., Singh, B.N., Verma, O.P., Tripathi, S. and Dwivedi, D.K. (2011). Correlation and path coefficient analysis in scented rice (Oryza sativa L.) under sodicity, Environment and Ecology. 29(3B):1550-1556.

12.Mohammadi, S. A., Prasanna, B. M., \& Singh, N. N. (2003). Sequential path model for determining interrelationships among grain yield and related characters in maize. Crop science, 43(5), 1690-1697.

13.Mohapatra, D. and Bal, S. 2006. Cooking quality and instrumental textural attributes of cooked rice for different milling fractions. Journal of Food Engineering 73: 253-259

14.Panse V.G. and Sukhatme P.V. (1967). Statistical methods of agricultural workers. $2^{\text {nd }}$ edition, pp:381, I.C.A.R. Publ. New Delhi.

15.Searle S.R. (1961). Phenotypic, genotypic and environmental correlation. Biometrics, 17:174-480

16.Sravan, T., Jaiswal, H.K., Waza, S. A., Kumari, P. (2016). Analysis of Variability and Character Association in Indigenous Aromatic Rice (Oryza sativa L.) Electronic Journal of Plant Breeding. 7(1):159-164

17.Tripathi, N., Verma, O.P., Singh, P.K. and Rajpoot, P. (2018). Studies on correlation and path coefficient analysis for yield and its components in rice (Oryza sativa L.) under salt affected soil. Journal of Pharmacognosy and Phytochemistry. 7(3): 1626-1629. 